Gabriel Huarte*

\title{
NATURALEZA DEL CONOCIMIENTO HISTÓRICO. Su enseñanza y aprendizaje
}

\begin{abstract}
Resumen
La elaboración del articulo responde a las inquietudes despertadas en mi al reflexionar sobre las conclusiones parciales de la reciente investigación que llevé a cabo en el campo de la enseñanza de la Historia en el nivel medio del sistema educativo argentino, convulsionado en los últimos años por los aires de las denominadas "reformas educativas". El trabajo se inicia planteando como disparadores tanto la utilidad o el para qué de enseñar historia como también analizar someramente las naturaleza de este conocimiento partiendo de la ambigüedad del término que la define. Luego de plantear una breve discusión sobre la preponderancia de las caracteristicas analíticas o narrativas de este saber a través de su evolución histórica, se intenta una conclusión donde se plantean interrogantes sobre el hoy de la enseñanza de la historia y el desafío que representa para nuestros alumnos adolescentes visitar "ese extraño país llamado pasado".
\end{abstract}

Palabras claves: Historia, enseñanza, sistema educativo argentino, discusión, investigación, estudiantes adolescentes.

\section{THE NATURE OF HISTORICAL KNOWLEDGE: ITS TEACHING AND LEARNING}

\begin{abstract}
The production of the article is a response to the awaken concerns in me to reflect on the partial conclusion of the. recent research that I carried out in the teaching field of History in high school in the argentine educational system shaken by waves of the called "educational reforms". The task is started presenting as axis its usefulness or why to teach history, but also analyzing the nature of this knowledge slightly, arising from the ambiguity term that clarifies it. After, it is expounded a brief discussion about the preponderance of analytical and narrative characteristics on this knowledge through its historical evolution. It is attempted a conclusion that establishes, questions about the present of teaching history and the challenge which represents for our adolescent students visiting "that strange country called past".
\end{abstract}

Key words: History, teaching, argentinian school system, discussion, research, adolescent students.

* Magister en Educación. Profesor de la Universidad de Buenos Aires. ghuarte@fch.unicen.edu.ar Texto original recibido: 10-09-06 y aprobado: 14-11-06. 
El trabajo que presentamos se vincula estrechamente a una de las mayores preocupaciones que han configurado nuestra labor como investigadores en el campo de la enseñanza de la historia en los últimos años. Nos referimos a la naturaleza del conocimiento histórico y el complejo problema de su traslado a la enseñanza. Aquí debemos precisar que las investigaciones mencionadas se ubican en el marco constituido por la implementación de las reformas educativas que tuvieron lugar en América Latina durante los recientes años noventa, las cuales no carecieron de complejidad y en muchos casos acarrearon más interrogantes que respuestas positivas, por lo menos en el caso específico de la República Argentina, como lo estarian indicando publicaciones recientes ${ }^{1}$.

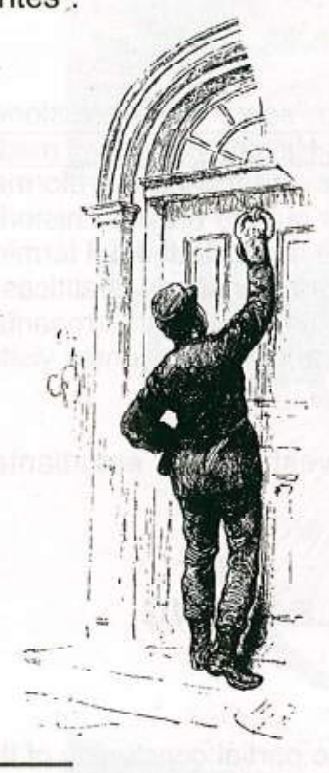

1 Entre otros: LILIANA MARTIGNONI (2002). La transformación educativa de los noventa en Argentina. Tercer Ciclo de la Educación General Básica. En: Inés Castro (coord. Visiones Latinoamericanas). México: UNAM; Alejandra Birgin. (1999). El trabajo de enseñar. Entre la vocación y el mercado: las nuevas reglas del juego. Buenos Aires: Troquel; Gabriel Huarte, et al. (1998). El tercer ciclo de la educación General básica bonaerense: ¿Encuentro de dos mundos? En: A. CORBALAN Y H. Russo, (1998). Educación, actualidad e incertidumbre. Tandil, Argentina: UNCPBA.
Respecto del caso argentino, es necesario señalar que apenas transcurridos algo más de doce años de la promulgación de la denotada y también denostada "Ley Federal de Educación", ya se está en vías de su remplazo por una nueva norma -a la que se denominaría "Ley Nacional de Educación"-, y cuyo proyecto ya obra en manos del poder ejecutivo para ser sometido a un amplio debate social y su posterior elevación al Congreso.

Según las informaciones del Ministerio de Educación, Ciencia y Tecnología (MECyT) y sus asesores más destacados, la nueva norma por discutirse en el Parlamento debería corregir las serias anomalias que la Ley Federal provocó en su hasta ahora breve reinado. Entre las más notorias, la anarquía curricular y la disparidad de criterios en la interpretación de la naturaleza de la ley por las jurisdicciones que conforman el sistema nacional².

Respecto de la situación descrita, cabe agregar, aunque sea como anécdota ilustrativa, que la jurisdicción correspondiente al Gobierno Autónomo de la Ciudad de Buenos Aires (ex municipalidad de la Ciudad de Buenos Aires) no observó los lineamientos del mencionado instrumento legal, manteniendo la antigua estructura, al mismo tiempo que se impulsaba la actualización de los docentes y una mejor administración del sistema.

Quien aqui escribe no es especialista en el análisis institucional ni tampoco experto en las cuestiones legales vinculadas al sistema educativo. Ante esa inapelable razón dejaremos dichas problemáticas a nuestros colegas más idóneos, y nos circunscribiremos a reflexionar sobre

${ }^{2}$ La ley federal dividió al país en 24 distritos educativos, los cuales, respecto a curricular, si bien debían respetar los llamados Contenidos Básicos, CBC, podian adecuarlos a sus realidades particulares produciendo sus propios diseños. la naturaleza del saber histórico y las certezas e incertidumbres que provoca su implementación como materia de enseñanza en un sistema educativo que -luego de un inmovilismo casi secular- ha quedado sujeto en los tiempos actuales a frecuentes cambios de marcha y orientación.

\section{EL DESARROLLO DEL CONOCIMIENTO HISTÓRICO: ALGUNAS NOTAS SOBRE SU EVOLUCIÓN}

Como inicio de la discusión, permítasenos utilizar como disparadores las "provocaciones" que ex profeso un destacado historiador de nuestro tiempo insertaba en las primeras páginas de un libro hoy emblemático ${ }^{3}$. La primera de esas "provocaciones" se expresaba a través de una caricatura representando a un niño que se planteaba perplejo: "En la clase de matemáticas yo me lo creo todo... bueno, pues me exigen la demostración... en cambio en la de historia, lo que me exigen es sólo que me lo crea...".

Acto seguido -ya dentro de la estructura del prólogo-, el autor caracterizaba de la siguiente manera la función social de la historia, la cual: "... Desde sus comienzos, en sus manifestaciones más primarias y elementales, la historia ha tenido siempre una función social -generalmente la de legitimar el orden establecido- aunque haya tendido a enmascararla, presentándose con la apariencia de una narración objetiva de hechos concretos" (p. 14).

Ejemplos de estas "narraciones objetivas" Io constituirian tanto las tradiciones orales - que en las sociedades ágrafas servian para transmitir y justificar su estabilidad-, como las representaciones figuradas en los monumentos públicos, así sean

3 J. Fontana. (1982). Historia. Análisis del pasado y proyecto social. Barcelona: Crítica. 
del Egipto faraónico, el Imperio Romano o de los modernos Estados Nacionales.

Si se coincide con la visión del historiador citado, puede postularse que la función social de la historia ha sido en gran medida la de la justificación del orden vigente y la de conservar la estabilidad de un proyecto social, sobre todo a través de su enseñanza, situación que, sin embargo, debería cambiar, ya que como él mismo concluye más adelante:

Los que trabajamos en este terreno -es decir, el de la historia-compartimos a un tiempo la preocupación por la sociedad en que vivimos, y la creencia de que nuestra disciplina tiene una extraordinaria importancia en la educación, tanto por su voluntad totalizadora (única en su intento de abarcar globalmente, y en sus interacciones, todos los elementos que se integran en la dinámica de una sociedad), como porque puede ser empleada adecuadamente, una herramienta valiosísima para la formación de una con ciencia crítica (p. 248).

Los comentarios precedentes sirven de introito para efecto de abordar aspectos de la historia como disciplina científica, como materia objeto de enseñanza y aprendizaje, y también, si ello es posible, intentar alguna reflexión sobre su "función social" más allá de los ámbitos estrictamente académicos y escolares. Una manera no demasiado original de iniciar este recorrido sería aproximarse a una definición del significado de la historia en cuanto a su consideración como disciplina científica. Sin embargo, rápidamente caeríamos en cuenta de lo desmesurado e inútil del esfuerzo, si es que con el mismo pretendiéramos abarcar una globalidad de expectativas.

No obstante, podríamos llegar a acordar que hay tantas definiciones de historia como corrientes o posturas historiográficas se han desarrollado. Pese a ello, algo con seguridad alcanzariamos: el des- cubrimiento de la ambigüedad del término que la designa antes que una acertada definición de la misma como disciplina. Esto es así debido a que se designa con el término "historia" al objeto del conocimiento y a las actividades disciplinares que se ocupan de la construcción y la enseñanza de su saber. Tal ambigüedad es marcadamente fuerte en nuestra lengua donde el término nombra al conocimiento erudito, al objeto de estudio y a las narraciones que se construyen a partir del devenir de los acontecimientos o a las ficciones literarias tales como el cuento y la novela, que también "cuentan una historia".

En la Grecia clásica, historia era sinónimo de pesquisa, cuya función era llegar a la verdad de hechos que, a diferencia de los narrados por la epopeya y la leyenda, se suponía realmente sucedidos Esa labor era ejercida por cierto personaje, el hystor, al que podria asociarse con la imagen del detective de nuestro tiempo ${ }^{4}$. Lo significativo de su trabajo radicaba en que obraba a partir del testimonio de los testigos de los hechos, lo cual establecía una limitación temporal a esas indagaciones, es decir, el límite impuesto por la duración vital de los testigos.

En la lengua latina aparece la diferenciación entre el pasado como totalidad: res gestae y el estudio del mismo como rerum gestarum. Esta diferencia ha permanecido con cierta sutileza en algunas lenguas modernas, dentro de las cuales es significativo el ejemplo del inglés donde el producto de la investigación sobre el pasado y su proceso de enseñanza se designa como History, mientras

${ }^{4}$ R. G. Coluingwood. $(1946,1976)$. Idea de la Historia. México. Fondo de Cultura Económica. En el capitulo dedicado por este filósofo e historiador británico a la metodología de la investigación en historia, se plantea la afinidad entre el trabajo del historiador y el del investigador policial. que las narraciones vinculadas a la ficción se las reconoce como story's. Otra situación de no menor importancia la constituye la tradición cultural de Occidente que, desde sus inicios en la antigüedad clásica y hasta bien entrado el siglo XIX, consideró a la historia dentro de las artes antes que disciplina científica; de ahí su ubicación en el seno de las humanidades, formando parte de las bellas letras.

No obstante la asignación de un lugar en el universo estético antes que en el científico, la historia ya en sus primeras manifestaciones como tal (siglo V a. de J.C.) expresa su singularidad. En efecto, Heródoto de Halicarnaso -considerado por el gran orador latino Cicerón como "padre de la historia"-escribia que:

... La publicación que Heródoto de Halicarnaso va a hacer de su Historia se dirige principalmente a que no llegue a desvanecerse con el tiempo la memoria de los hechos públicos de los hombres, ni menos a obscurecer las grandes y maravillosas hazañas, así de los griegos, como de los bárbaros. Con este objeto refiere una infinidad de sucesos varios e interesantes, y expone, con esmero, las causas y motivos de las guerras que se hicieron unos a otros... 5 .

Pueden apreciarse aquí presupuestos fundamentales de toda narración que se precie de histórica; por ejemplo, evitar que la memoria de los hechos públicos de los hombres que tuvieron como actores a unos y otros como así también sus maravillosas hazañas se pierdan, o haciendo hincapié con esmero en las causas y motivos que vinculaban a dichos sucesos.

${ }^{5}$ Heródoto. (1968). Los nueve libros de la Historia. Buenos Aires: El Ateneo, traducción del griego de Bartolomé Pou. Libro $1^{\circ}$, Clío. El autor designó con el nombre de cada una de las nueve musas a los libros que componen la obra, a saber: Clío, Euterpe, Talia, Melpómene, Terpsicore, Erato, Polimnia, Urania y Caliope. 


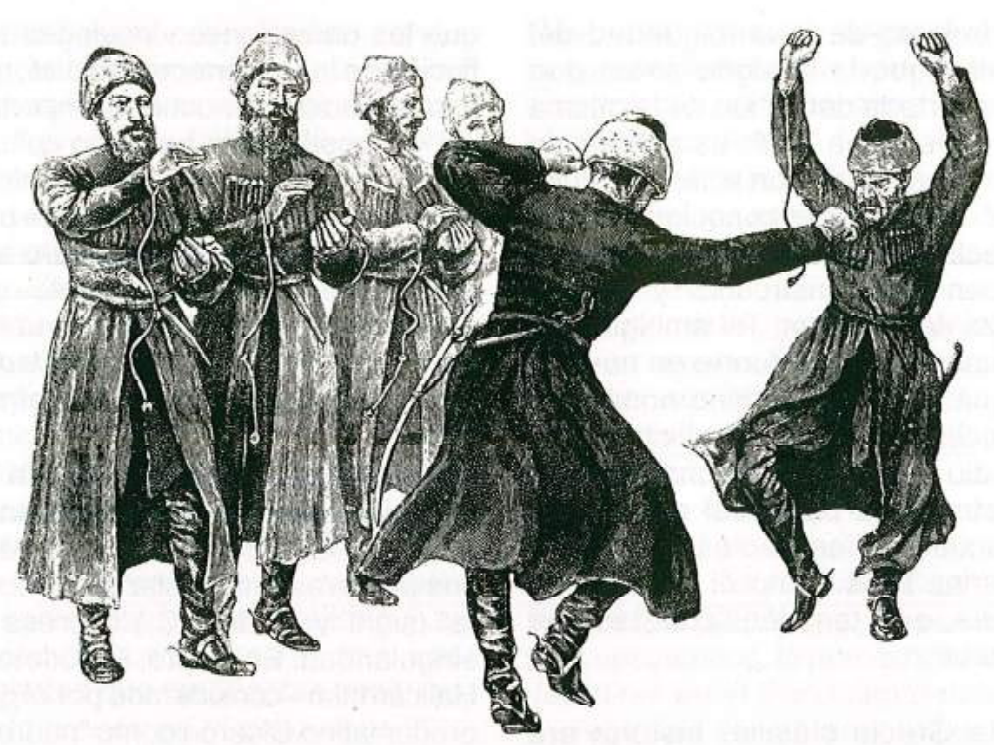

Pasó poco tiempo y la construcción de la narración histórica exhibiría notables progresos a partir de las cavilaciones de Tucidides, integradas en una singular amalgama de incertidumbres y certezas. Este autor intentó explicar las causas y consecuencias que habian conducido a espartanos $\mathrm{y}$ atenienses a enfrentarse en una cruel guerra de la cual él a su vez era espectador, actor y comentarista:

...Por lo que se refiere a los hechos, no he creido conveniente explicarlos según el relato de uno cualquiera, ni tampoco según mis impresiones personales, a no ser que yo mismo los hubiese presenciado. Si procedian de testigos he llevado a cabo, sobre cada punto, una encuesta lo más severa posible. Esta busca era penosa porque estos testigos no daban idéntica explicaciones de los mismos hechos, sino que fluctuaban de una a otra opinión según su simpatía o su memoria...

Sin embargo, su ambición superará ampliamente la preocupación por la verdad relativa de los hechos que expone, ya que intentará que su relato: "...Sea útil para cualquiera que desee tener una visión certera de los acontecimientos pasados y de los sucesos parecidos o análogos cuyo retorno provocará el juego de la naturaleza humana...", considerando al saber obtenido a partir de los hechos narrados como "un bien adquirido para la eternidad"6. Al escribir fundado en un método riguroso aplicado a acontecimientos contemporáneos de los que a su vez es actor y víctima, Tucidides intenta "comprender" la guerra y, al narrarla, extender este acto de comprensión a los demás. Pero en ello no se agota su contribución a la consolidación de la historia como empresa intelectual autónoma; su escritura implica una concepción que aún hoy sigue siendo influyente: la historia propuesta como un laboratorio de experimentos destinados a repetirse, antologia de ejemplos y guía de políticos y pensadores ${ }^{7}$.

Los romanos incorporaron a la tradición heredada de los griegos el pragmatismo característico de su concepción política; es así que la historia estará al servicio del Estado certificando la grandeza de Roma y su "destino manifiesto" de dominado-

- Tucidides. (1963). Las querras del Peloponeso, Libro $1^{\circ}$. Historia general de las civilizaciones, vol. 1. Barcelona: Iberia. ${ }^{7}$ A. Aymard y J. Auboyer. $(1958,1977)$. El clasicismo espiritual y estético: La vida intelectual. En: Maurice Crouzet (dir.). Historia general de las civilizaciones. Oriente y Grecia Antigua. Barcelona: Destino, vol. 1, libro II, cap. IV, p. 433. ra del mundo; además le adjudicarán una función laica y moralizante expresada en aquello de la historia como magister vitae. El advenimiento del cristianismo en el seno del Imperio produjo un cambio radical, cuya consecuencia más destacada fue el abandono de la cosmovisión cíclica de la naturaleza y la sociedad, típica del pensamiento greco-latino, por una concepción lineal del desarrollo de la historia humana que reconocía tres momentos definitorios: la Creación, la llegada del Mesias y el Juicio Final; en otras palabras, el destino de los hombres estaba sujeto al designio divino, situación que sometía a la historia a un destino escatológicamente predeterminado. Tendría que llegar el Renacimiento para que la historia recuperase sus posibilidades criticas $y$, sobre todo, su utilidad al servicio de la política y del Estado ${ }^{8}$. Sin embargo, es preciso tener en cuenta que la concepción lineal del desarrollo de los sucesos en el tiempo -ora al servicio de la providencia, ora al servicio de la razón, como sucedió durante la hegemonia de la llustración- permaneció incólume hasta el arribo de la concepción dialéctica, fundamentalmente a través del idealismo hegeliano y el materialismo histórico.

Como ya se señalara, la configuración política de la operación historiográfica fundada en los hechos importantes, los grandes nombres y los conflictos militares y diplomáticos, se consolidó a través de más de dos mil años, compartiendo en alguna medida el campo con otra concepción más afín a complacer la curiosidad de sus lectores, presentada en una versión más estética y hasta cierto punto más exótica de las cuestiones del pasado. La historia de naturaleza eminentemente politica se constituirá en la pedagogía cívica ideal que convalidará la legitimidad de los "Estados-Nación" surgidos en el siglo XIX, prolongando su vigencia

${ }^{8}$ P. BURKe (1993). Formas de hacer historia. Madrid: Alianza Editorial, cap. 1. 
durante gran parte de la siguiente centuria, sobre todo en el campo de la enseñanza donde privilegiará una función formativa en lugar de otra más explicativa o interpretativa ${ }^{9}$.

Es, sin embargo, el espacio temporal contenido en el siglo $X X$ donde tendrian lugar los "combates por la historia", posibilitando el surgimiento de propuestas alternativas que desalojarán de su atalaya a la vieja historia de los acontecimientos políticos presidida por la norma que consagraba "la reunión ordenada de los hechos para que éstos hablen por sí mismos". Esas propuestas alternativas harán hincapié primero en las estructuras económicas y sociales, a las que luego agregarían las estructuras mentales y sus universos simbólicos, configurando de esa manera nuevos campos de indagación, situación a partir de la cual se conformaría un saludable maridaje entre los historiadores y los demás cientistas socialès.

A partir de la nueva situación, la descripción que el historiador francés Pierre Vilar lleva a cabo sobre esas nuevas formas de organizar el estudio del pasado, adquiere la contundencia de una definición:

El objeto de la historia es el estudio de la dinámica de las sociedades en el tiempo. La materia histórica la constituyen los tipos de hechos que es necesario estudiar para dominar científicamente este objeto (...) Primero los hechos de masas: masas de los hombres (demografía) masa de los bienes (economia), masas de los pensamientos y las creencias (fenómenos de las mentalidades, lentos y pesados; fenómenos de opinión, más fugaces. Segundo, los hechos institucionales, más superficiales pero más rígidos, que tienden a fijar las relaciones humanas dentro de

9 G. Huarte y C. VAn der Horts. (2002). Historiografía y enseñanza de la historia en la Argentina, 1880-1910. En: Visiones latinoamericanas, op. cit., pp. 227 -252. los marcos existentes (...) Tercero, los acontecimientos: aparición y desaparición de personas, de grupos (económicos, políticos), que toman medidas, decisiones o desencadenan acciones (...) La historia no puede ser un simple retablo de las instituciones, ni un simple relato de los acontecimientos, pero no puede desinteresarse de estos hechos que vinculan la vida cotidiana de los hombres a la dinámica de las sociedades de las que forman parte ${ }^{10}$.

Si se adhiere a esta postura, estaríamos de acuerdo en considerar a la historia como una disciplina científica consolidada, muy atenta a la periódica revisión de sus resultados y a la incorporación de nuevos temas. Esta condición la convertiría en una de las que Dennis Shelmits propuso como formas de conocimiento, dotadas de las siguientes características ${ }^{11}$ :

a) Un conjunto de conceptos distintivos que definen la experiencia humana de una manera particular, tal como masa y momento en física, señorío y mercantilismo en historia. Cada forma de conocimiento tiene su propio cuerpo conceptual, al igual que cada lengua posee su propio léxico.

b) Maneras caracteristicas de relacionar y articular los conceptos; por ejemplo, la exposición y explicación histórica es esencialmente causal y de desarrollo, y aunque estas ideas no son exclusivamente de la historia, tienen un significado y una aplicación peculiares a la materia (en tanto que

${ }^{10}$ P. VILAR. (1982). Iniciación al vocabulario del análisis histórico. Barcelona: Crítica, p. 43.

11 D. J. Shellmits. (1987). El proyecto de enseñanza de la historia 13-16 años del British Council. En: La geografia y la historia, dentro de las Ciencias Sociales hacia un curriculum integrado. Madrid: MEC. Es conveniente aclarar aquí que el concepto de formas de conocimiento fue acuñado por R. H. HiRTs (Londres, 1965). la causalidad en física sería una noción de naturaleza positivista o neo-positivista, la historia seleccionaría condiciones necesarias y buscaria establecer vinculos de posibilidad lógica y no de necesidad legítima. Del mismo modo, la noción de desarrollo no puede ser uniformemente aplicada a las entidades orgánicas y a las culturales, sino que presentaria desviaciones de significado del campo de la historia al de la biología). Este segundo aspecto de las formas de conocimiento puede ser comparado, de algún modo, con la sintaxis de las lenguas.

c) Ciertas formas características de aducir pruebas en apoyo de las proposiciones y de establecer su validez. La reproducción experimental es el método de la física; en cambio el historiador no experimenta sino que establece una empatia con los hechos, y los reconstruye en lugar de reproducirlos.

d) Ciertas formas características de realizar investigaciones, generar hipótesis y establecer enunciados; mientras que el químico puede utilizar los rayos $X$, la paleografia es una técnica distintiva de la historia.

Los puntos b) y c) se refieren a lo proposicional y procedimental continentes del núcleo esencial de las llamadas formas de conocimiento. El punto d) es meramente ilustrativo en cuanto a las diferencias técnicas, mientras que en el punto a) se hace referencia a los productos distintivos de las diferentes formas y no a la lógica interna de determinados modos exclusivos de conocer y comprender el mundo ${ }^{12}$.

${ }^{12}$ G. HUARTE. (1998). La naturaleza epistemológica del conocimiento histórico y su transposición didáctica. En: Anuario del IEHS, N. ${ }^{\circ} 13: 319-334$. Tandil, Argentina: Grafikart, UNCPBA. 
No obstante la adhesión aparentemente generalizada en la consideración de la historia como una disciplina de naturaleza científica que mediante el análisis de las estructuras perseguía una explicación totalizadora del comportamiento de las sociedades a través del tiempo, comenzaron a surgir fuertes discrepancias con respecto al discurso portador de esa "nueva historia"13.

Con el fin de ser sintéticos, circunscribiremos el análisis del problema a las dos corrientes que se disputaban la razón. Por una parte están quienes postulaban que el conocimiento histórico debe procurar la explicación de los procesos que estudia, individualizando las causas determinantes de los mismos; conciben así a la historia como una ciencia capaz de proponer generalidades o regularidades explicativas a través de su exposición en un discurso analítico. La otra corriente hace hincapié en el carácter eminentemente humano del conocimiento histórico, resaltando la comprensión de la intencionalidad de los sujetos intervinientes, sean ellos eminentes 0 anónimos. Aquí el discurso adquirirá una naturaleza preponderantemente narrativa; véanse en detalle las características más significativas de ambas corrientes:

En las ciencias físicas, la narrativa carece en absoluto de lugar, excepto en las anécdotas introductorias a la presentación de los hallazgos; un físico o biólogo consideraría extraño contar una historia sobre sus datos en vez de analizarlos. La biologia se convirtió en una ciencia cuando dejó de ser practicada como "historia natural", es decir, cuando los científicos de la naturaleza orgánica abandonaron el intento de construir "la verdadera historia" de lo "que sucedia", y empezaron a buscar leyes puramente causales y no teleológicas (intencio-

${ }^{13}$ E. Hobsbawm. (2003). Años interesantes: una vida en el siglo XX. Buenos Aires: Crítica-Planeta. Capítulo 17, pp. 270-271. nales) que pudieran explicar la evidencia proporcionada por el registro fósil, los resultados de las prácticas de cultivo, etc. Ciertamente, como subraya Mandelbaum, una presentación secuencial de un conjunto de acontecimientos no es lo mismo que una presentación narrativa de éstos. Y la diferencia entre ellos está en la ausencia de cualquier interés por la teleología como principio explicativo de la primera ${ }^{14}$.

Llegados a este punto, resulta indispensable detenerse en el concepto de narrativa que el autor que aquí se sigue nos propone para el caso de la historia:

En el ámbito de los estudios históricos, la narrativa no ha solido ser considerada ni como producto de una teoría ni como la base de un método, sino más bien como una forma de discurso que puede utilizarse o no para la representación de los acontecimientos históricos, en función de si el objetivo primario es describir una situación, analizar un proceso histórico o bien contar una historia. Según esta concepción, la cantidad de narrativa de una determinada historia varia, y su función cambiará dependiendo si se concibe como fin en sí o sólo como medio para otro fin. Obviamente, la cantidad de narrativa será mayor en los relatos que pretenden "contar una historia" (...). Cuando el objetivo a la vista es narrar una historia, el problema de la narratividad se expresa en la cuestión de si pueden representarse fielmente los acontecimientos históricos como manifestación de estructuras y procesos de acontecimientos más comunmente encontrados en ciertos tipos de discursos "imaginativos", es decir, ficciones como la épica, los cuentos populares, los mitos, el romance, la tragedia, la comedia, la farsa, etc. Esto significa que lo que distingue a las formas "históricas" de las "ficcionales" es ante todo su contenido, en vez de su forma... ${ }^{15}$

${ }^{14} \mathrm{H}$. WHITE. (1992). El contenido de la forma. México: Fondo de Cultura Económica, pp. 41-42.

${ }^{15} \mathrm{H}$. WHITE, op. cit., p.43.
Sintéticamente, la diferencia entre la narración histórica y la de ficción estaría dada por la naturaleza de los contenidos que abordan: supuestamente verdaderos los de la historia y no necesariamente así los de ficción. De lo expuesto, surge la importancia que vuelve a asignársele a la narración en la construcción y explicación del conocimiento histórico. Veamos esto con más detalle.

Una pregunta que podríamos hacernos es: ¿Cuál es la relación existente entre la explicación histórica y la comprensión narrativa? Este debate lleva ya varias décadas dentro de la historiografía y la filosofia de la historia, y a fuer de verdad, podría afirmarse que en los últimos tiempos la postura narrativa se ha visto remozada frente a las propuestas de explicación histórica de indole más estructuralista o analítica. Hay que aclarar que esta postura reivindica a la historia como la disciplina que se ocupa exclusivamente de las acciones humanas ocurridas en el pasado. Desde el punto de vista de Veyne (1971), "Los historiadores relatan acontecimientos verdaderos donde los actores son los hombres", de lo que surge un aporte de singular importancia para la enseñanza y el aprendizaje: la comprensión de los contenidos históricos implican necesariamente comprender las acciones de los hombres expuestas a través de un relato.

Desde una posición cercana a Veyne, Paul Ricoeur (1995) propone que captar en su conjunto los agentes de las acciones, las propias acciones y sus consecuencias en un contexto social dado, implica necesariamente la construcción de una trama narrativa que integre estos elementos tan heterogéneos en una totalidad significativa: "la historia". Ricoeur extrae el concepto de trama del término mímesis mediante el cual Aristóteles designa a la representación o imitación de la acción. Sin embargo, la concepción de que la trama es imitación 
de la acción trae aparejados otros interrogantes, como por ejemplo: ¿Qué relación existe entre la comprensión narrativa y la acción? ${ }^{16}$.

Para algunos autores, tanto el relato histórico (en el sentido definido por Paul Veyne) como el relato de ficción se encuentran precedidos por el uso de la narración en la vida cotidiana (Ricoeur, 1984; Bruner, 1990; White, 1992). Para los citados, la representación del pasado hunde sus raíces en el campo de la acción humana, situación que implica la necesidad de los sujetos de poseer una competencia previa que les permita transformar una secuencia de eventos en un relato. Esta competencia se inscribe dentro de lo que Ricoeur denomina la "precomprensión del mundo de la acción", la cual permite a los sujetos distinguir entre el campo de las acciones humanas y el campo del movimiento físico ${ }^{17}$.

Los autores a los que hemos recurrido se preocuparon por caracterizar algunos elementos de la representación narrativa del conocimiento histórico; no obstante, la narratividad no se agota en sí misma, sino que su aporte es mucho más amplio ya que también da cuenta de la experiencia humana dentro del contexto social. En palabras de Hayden White: "la narrativa-que surge como dice Roland Barthes entre nuestra experiencia del mundo y nuestros esfuerzos por describir lingüísticamente esta experiencia- sustituye incesantemente la significación por la copia directa de los acontecimientos". De esta

${ }^{16}$ A los efectos de ampliar el significado que los griegos adjudicaban al término mimesis, léase lo que sigue: "Aristóteles afirma, por ejemplo, que el arte es imitación. Esto -insistimos- quiere decir representación de la realidad tal como el poeta la ve o como cree que deberia ser". Aristóteles. Poética. Traducción y notas de Alfredo Llanos. Buenos Aires: Santiago Rueda Editores.

${ }^{17}$ P. Ricoeur. (1995). Tiempo y narración. Madrid: Siglo XXI Editores, tomo I, capítulos 2 y 3 , pp. 80-168. conclusión puede seguirse y confirmarse el papel fundamental de la narrativa en la representación de los acontecimientos humanos.

\section{EL CONOCIMIENTO HISTÓRICO Y EL PROCESO DE SU ENSEÑANZA}

Luego del sobrevuelo obligadamente limitado que hemos realizado sobre aspectos del desarrollo y de la evolución de la naturaleza del conocimiento histórico, centralizaremos seguidamente el análisis en el desafío que significa su transposición didáctica. Un primer problema que se presenta a este proceso de enseñanza y aprendizaje consiste en la consideración de los denominados saberes previos que los alumnos ya tienen incorporados en su estructura cognitiva. Como es sabido, la importancia de este tipo de conocimientos reside en que los mismos son la base del denominado aprendizaje significativo (Ausubel, 1983), y que desde el punto de vista de quien aquí escribe, requiere para su análisis por lo menos dos lecturas.

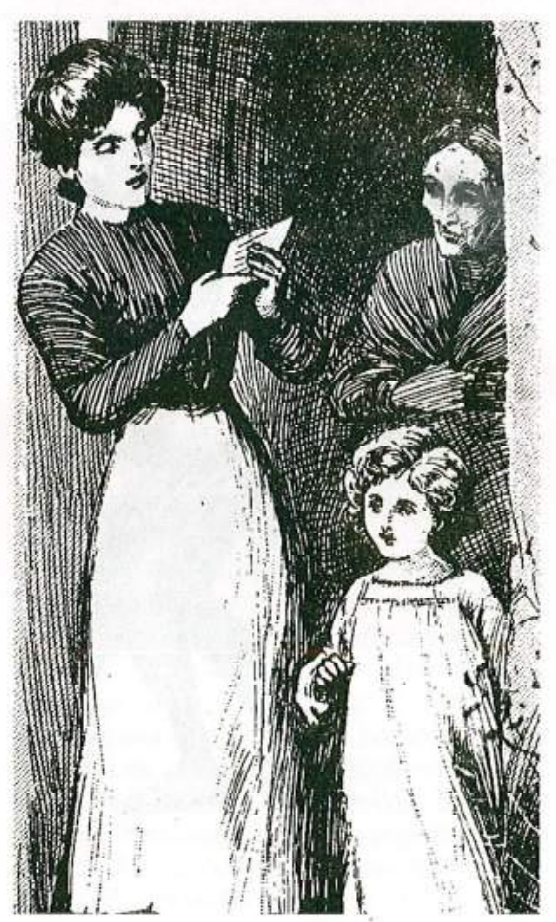

La primera pone su atención en los conocimientos específicos que sobre la asignatura ya poseen los alumnos. La segunda, tan importante o más que la anterior, destaca la importancia de los saberes provenientes del entorno sociocultural como determinantes en las estructuras cognitivas de quienes aprenden según lo estudios pioneros en esta materia llevados a cabo por Lev Vygotsky, así como también del concepto de cotidianidad elaborado por Paulo Freire:

En último análisis, cuanto más rigurosamente competentes nos consideremos nosotros mismos y a nuestros pares, tanto más debemos reconocer que si el papel del educador progresista no consiste jamás en alojarse, con armas y bagajes, en la cotidianidad popular, tampoco es el de quien, con desprecio innegable, considera que no tiene nada que hacer con lo que alli ocurre. La cotidianidad como lo dejó muy en claro Karel Kosik en su Dialéctica de lo concreto (1973), es el espacio tiempo en que la mente no opera epistemológicamente frente a los objetos, los datos, los hechos. Se da cuenta de ellos pero no capta su razón de ser más profunda. Esto no significa, sin embargo, que yo no deba dejar de considerar a la cotidianidad y la forma en que me mueva dentro de ella en el mundo como un objeto de mi reflexión; que no procure superar el puro darme cuenta de los hechos a partir de la comprensión crítica que de él voy alcanzando... ${ }^{18}$.

Luego del toque de atención sobre la importancia que adquiere la consideración de los conocimientos previos en toda propuesta didáctica, ahora analizaremos otro aspecto crucial -como lo es la utilización del concepto de causalidad- en la enseñanza y el aprendizaje de las disciplinas históricas. Respecto de este concepto debe tenerse en claro que el mismo postula la explicación de los procesos que estudia por sobre el de la comprensión de los mismos. En este sentido, es de

${ }^{18}$ P. Freire. (1999). Política y educación. México: Siglo XXI Editores, p. 55. 
suma importancia subrayar que las corrientes epistemológicas que proponen la aplicación del concepto de causalidad diferencian la explicación de la comprensión.

Ahora bien, respecto de la posibilidad de lograr explicaciones a partir del análisis de los procesos históricos, pueden identificarse dos corrientes principales: por una parte, la que adhiere a posturas que reconocen raices en el positivismo y el positivismo lógico; aquí se plantea la identidad entre los esquemas o procedimientos explicativos utilizados en las ciencias naturales y en las ciencias sociales. Mientras que en el otro extremo, constituido por tendencias filosóficas más heterogéneas, las propuestas establecen una marcada delimitación entre los esquemas o modelos explicativos propuestos para la historia y las ciencias sociales y los formulados para las ciencias naturales.

La línea de pensamiento citada en primer término propone como fundamentos la unidad de método y la búsqueda de leyes generales que sustenten las explicaciones científicas. En otras palabras, esto significa que la explicación causal busca necesariamente el establecimiento de una legalidad formal que explique el comportamiento social; en definitiva, para este enfoque, el esquema causal de las ciencias naturales se convierte en el modelo explicativo para todas las ciencias ${ }^{19}$. Sin embargo, y dadas las características diferenciadas que presentan las ciencias sociales en relación con las naturales, han surgido posturas alternativas que enriquecen el modelo de explicación causal.

Una de las más elaboradas la constituyó el modelo de explicación teleológico o intencionalista propuesto por Von Wright (1979). En dicha proposición se plantea que explicar

${ }^{19}$ M. Carretero. (1996). Construir y enseñar las ciencias sociales y la historia. Madrid: Visor, cap. 3. teleológicamente una acción implica la comprensión de una determinada intención en el agente que la lleva a cabo, de tal forma que la intención se constituye en su rasgo más caracteristico. En palabras de Von Wright: "La acción es normalmente conducta comprendida o descripta a través del prisma de la intencionalidad".

Pese a la aparentemente convincente conclusión del autor, desde otros puntos de vista pretender explicar los procesos sociales a partir del análisis de las acciones de los actores y de los motivos que las impulsan sería una operación con serias limitaciones, ya que no es posible explicar las transformaciones que sufren las sociedades en términos de intenciones, creencias y propósitos de los agentes, si no se tiene en cuenta que éstas acciones se encuentran inmersas en una compleja red de determinantes sociales que constituyen razones objetivas condicionantes y limitantes del accionar de los sujetos. Teniendo en cuenta lo antecedentemente expuesto, sería pertinente atender las razones que propone la siguiente crítica al modelo de explicación intencionalista:

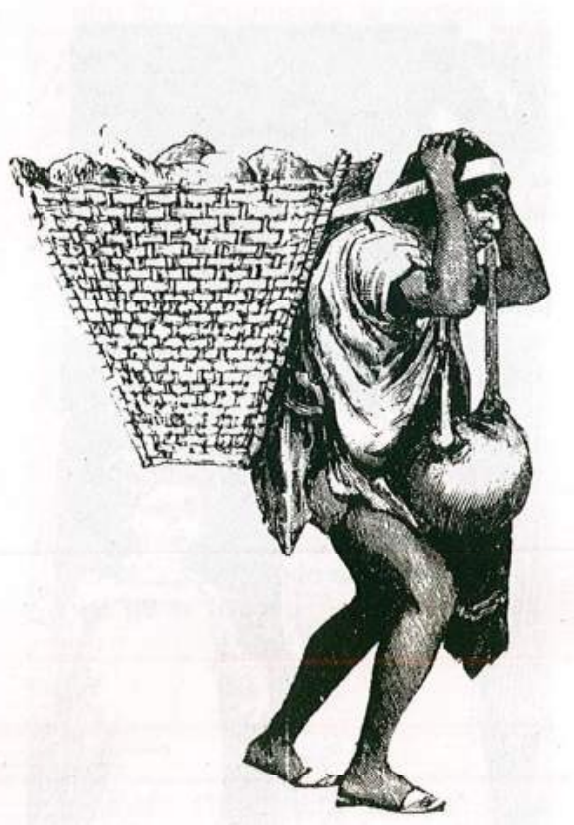

${ }^{20}$ C. Pereyra. (1988). Historia: ¿Para qué? México: Fondo de Cultura Económica, p. 28.

El problema de la ciencia de la historia no consiste en identificar quiénes son los agentes del proceso, pues sin duda alguna son los hombres y sólo ellos. La dificultad estriba en localizar los factores que determinan el carácter de su actividad y, por tanto, la explican. Restringir la búsqueda de esos factores determinantes al ámbito de las intenciones, planes o proyectos de los agentes es quedarse a medio camino en la explicación ${ }^{20}$

La oposición entre los que sostenian el modelo causal legalista y el intencionalista para la explicación en las ciencias sociales y la historia ha sido superada hace bastante tiempo por cientistas sociales e historiadores: en el caso especifico de la historia, se procura una explicación más integral de los procesos bajo estudio, situación que implica un análisis de la estructura social incluyendo no sólo las intenciones y motivaciones de los agentes, sino también el de las condiciones sociales existentes.

De esta manera se estaría postulando, más que una explicación mecánica del proceso analizado, la comprensión no sólo de las acciones de los actores involucrados en los hechos, sino también de las diversas variables intervinientes En este sentido, parece pertinente recuperar el pensamiento de Lloyd (1986), quien planteaba que las explicaciones causales y la posterior comprensión de los hechos históricos deberian privilegiar el análisis de tres situaciones:

a) En primer término, el conocimiento de las intenciones de los actores.

b) El conocimiento sobre las condiciones particulares bajo las cuales ocurren las acciones, los eventos y los procesos sociales.

c) La existencia de modelos generales y teorías sobre los individuos, las sociedades y los procesos so-

Pedagogía y Saberes N. 252006 
ciales, como también la sociedad y la acción ${ }^{21}$.

Queremos recordar aqui una lectura clásica que ilustra muy bien acerca de los problemas presentados por la construcción de una explicación causal integral sobre un proceso histórico dado: nos referimos al primer capitulo de una reconocida obra del filósofo Adam Schaff22. En él se ofrece un exhaustivo análisis del problema de la causalidad en la explicación del proceso de la Revolución Francesa; si bien es cierto que por razones atinentes al tiempo en que fue escrito (la presentación del libro en alemán data de 1971), su aporte sigue siendo imprescindible ya que pone en discusión los diferentes criterios de explicación causal que

${ }^{21}$ Sobre el problema de la construcción y la naturaleza de las explicaciones en historia, ver los trabajos de J. TopolsKY (1982). Historia económica, nuevos enfoques, nuevos problemas y Metodología de la historia. Madrid: Cátedra. En ellos, este autor propone tres formas de explicación ordenadas jerárquicamente pero vinculadas entre si: explicaciones causales, serian aquellas que aislan las causas de los acontecimientos; explicaciones genéticas, permiten reconstruir las etapas de los procesos bajo análisis, y explicaciones estructurales, son las que precisan, dentro de una estructura general, el funcionamiento de ciertos elementos dados o la inserción de hechos o procesos menores dentro de otros mayores. Con respecto a las explicaciones causales, Topolsky distingue dos posibilidades: las explicaciones basadas en el análisis de las motivaciones y acciones de los actores (individuales o sociales) y las explicaciones fundadas en modelos o teorías. Por ejemplo, el feudalismo como modelo de análisis de una formación social determinada ha sido utilizado para estudiar sociedades ubicadas en tiempos históricos distintos, como por ejemplo: la europea-occidental de los siglos XI al XIII, la de Europa Oriental, siglos XVI-XVIII (la denominada "segunda servidumbre"), y la existente en el Japón anterior a la dominación Meiji.

${ }^{22}$ A. Schaff. (1971, 1994). Historia y verdad. Introducción. Barcelona: Planeta-De Agostini, pp. 9-70. plantearon autores considerados ya clásicos a través de un recorrido que incluye a contemporáneos de los hechos como Barruell, Barnave o Le Maistre, para pasar luego a quienes más fuertemente polemizaron sobre el tema en el siglo XIX: Michelet, Tocqueville y Tayne, culminando con los tal vez más significativos de la primera mitad del siglo del XX: Jaurés, Mathiez, Labrousse y Soboul.

Como ya se indicara, por obligadas razones temporales este trabajo excluye a los más recientes; sin embargo, seria bueno apuntar que tanto François Furet, Michell Vovelle y el mismo Eric J. Hobsbawm, han retomado en sus trabajos más actuales sobre la Revolución los aportes de autores hoy considerados clásicos, y que con claridad expuso Shaff en su sintesis ${ }^{23}$.

A los efectos de completar este análisis sobre las posibilidades de explicar causalmente los procesos históricos contribuyendo a una mayor comprensión de tales sucesos, examinemos brevemente las posibilidades de la competencia narrativa respecto de la comprensión. Dada la necesidad de respetar el espacio que se nos ha asignado, sólo dejaremos planteados los siguientes interrogantes sobre la cuestión ${ }^{24}$.

- ¿Cómo comprenden nuestros alumnos la causalidad de los hechos o procesos históricos?

${ }^{23}$ E. Hobsbawm. (1992). Los ecos de la Marsellesa. Barcelona: Crítica; F. FURET. (1989). Pensar la Revolución Francesa. Barcelona: Crítica.

${ }^{24}$ Sobre el problema del concepto de competencia narrativa y su contribución al desarrollo de la conciencia histórica, ver: G. HUARTE. (2005). Identidades, representaciones y construcción de la conciencia histórica. Los contenidos de historia en el tercer ciclo de la educación general básica en la Argentina. En: Corbalán, MaríaAlejandra. Enredados por la educación, la cultura y la política. Buenos Aires: Editorial Biblos, p. 90.
- ¿La comprensión de los hechos históricos por parte de nuestros alumnos, privilegia experiencias de tipo narrativo?

- ¿Qué papel se otorga a los agentes sociales dentro de los relatos sobre eventos históricos?

- ¿Cómo perciben los alumnos las vinculaciones entre los agentes históricos, los motivos que los movilizan y las acciones que llevan a cabo?

Desde esta postura que privilegia la naturaleza narrativa del conocimiento histórico, los elementos o componentes esenciales son, sin lugar a dudas, los agentes históricos y sus motivos e intenciones. De esta constatación podría postularse que todo proceso de enseñanza y aprendizaje de la historia que haga énfasis en la comprensión basada en la narración, privilegiará la identificación de dichos agentes, sus vinculaciones con sus acciones y los motivos que los impulsan ${ }^{25}$.

\section{A MODO DE CONCLUSIÓN}

Para culminar estas reflexiones sobre los problemas teóricos que subyacen a las decisiones que deben tomarse en el espacio de la enseñanza de una asignatura de tan singulares características, atendamos a algunas de las claves que orientan el abordaje de la mencionada problemática. Desde nuestro punto de vista, una de las claves que señalan un camino correcto está expresada en la pregunta que se formula Mario Carretero (1996): “¿Cómo visitar

${ }^{25}$ Estas consideraciones se basan en MARIO CARRETERO Y LILIANA JACOTT (1996). Historia y relato, capítulo 5 de la obra Construir y enseñar las ciencias sociales y la historia. Madrid: Visor. La categoria de Agentes Históricos es definida por los autores como: agentes personales, agentes personales/sociales y agentes sociales. 
ese extraño país llamado pasado? y ¿cómo entender si fue bonito (o feo o trivial) mientras duró?".

Tal interrogante implica al menos dos cuestiones fundamentales: en primer lugar, fija un punto de partida que si y sólo si puede estar ubicado en el presente, ya que el pasado es el objeto de la "visita" en tanto que el futuro, debido a la naturaleza epistemológica de su ciencia, les está vedado al historiador y al maestro. Una segunda cuestión se refiere a cómo abordar el camino al "extraño país" y, sobre todo, cómo guiar a los alumnos en el tránsito de una senda tan escabrosa. Debe tenerse en cuenta que la metáfora propuesta por Carretero es una realidad abrumadoramente mayoritaria para nuestros alumnos y el público en general "no experto", y, por qué no, para más de un "experto".

Sin duda, al intentar descifrar esta clave nos encontramos ante una de las problemáticas cruciales que plantea la historia como disciplina y que es simétrica a historiadores y docentes. El historiador parte de un problema ubicado en su presente, lo que le obliga a buscar las huellas de su explicación en el pasado, situación que implica la formulación de los interrogantes que fundamenten la hipótesis (conjetura) que deberá verificar o desechar. Estos mecanismos

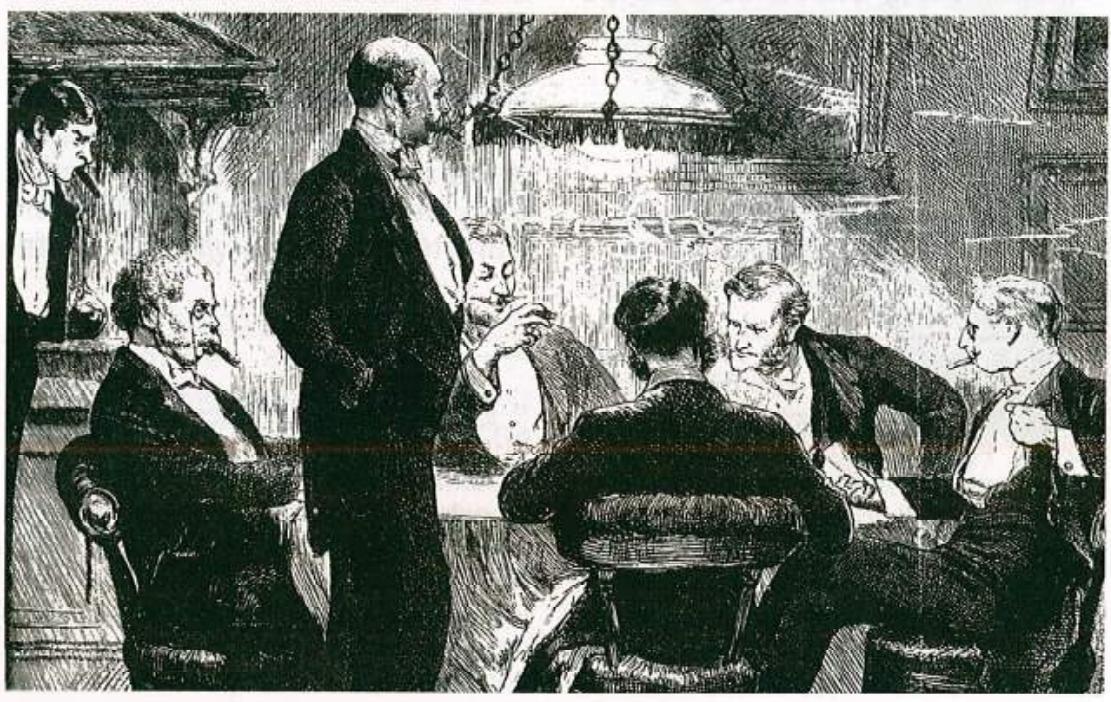

(procedimientos) son inherentes a la naturaleza intrínseca de la disciplina, y también deberian ser ineludibles para el maestro en el "traslado" que implica toda propuesta didáctica. Pero las preguntas que el historiador formula desde el presente también están condicionadas por el problema que ha obrado como disparador de esos interrogantes, y cuyas señales necesariamente deben buscarse en "ese extraño país". Intentaremos seguidamente ejemplificar esta situación:

Cuando en 1858 Bartolomé Mitre - padre fundador de la historiografia argentina-escribió la primera versión de su Historia de Belgrano y de la Independencia Argentina, su objetivo principal no fue ponderar la figura del personaje-prócer como uno de los hacedores de la libertad y de la independencia nacional, sino rescatar la idea de que la nación como unidad tenía su origen en el pasado colonial y se configuraba en los hechos de la revolución de independencia. De ahi que en momentos en que la posibilidad de lograr la unidad nacional estaba tan comprometida por el enfrentamiento entre la Provincia de Buenos Aires y las demás agrupadas en la Confederación Argentina, Mitre - uno de los actores principales del proceso- recurre a la historia para demostrar la necesidad imperiosa de resolver el problema (conflicto) de la organización nacional.

Otro aspecto no menos interesante para tener en cuenta en estas reflexiones es la confrontación entre el saber común (una combinación de saberes espontáneos, emergentes del sentido común y los saberes socialmente sancionados entre el público no especializado) y la enseñanza de una disciplina, especialmente en el caso de la historia. Para el mencionado universo, el conocimiento de la misma adquiere las características de un "viaje" al pasado al que presupone definitivo, inerte y acabado, elocuentemente expresado en el decir corriente de nuestros alumnos adolescentes: algo que ya fue.

Por otra parte, este conocimiento emergente del pensar común contrapone al proceso de enseñanza y aprendizaje versiones alternativas de determinados hechos o procesos que, por ese carácter de definitivo y terminado que configura este saber no académico, conduce a que gran cantidad de personas tengan una opinión formada sobre ese pasado, opinión que en la gran mayoría de los casos adquiere la consistencia de una estructura, la cual ejerce fuerte resistencia a la confrontación con nuevos conceptos e informaciones que pretenden modificarla. Este problema que frecuentemente se presenta en el ejercicio de nuestra práctica, nos advierte bien sobre la importancia de los denominados "conocimientos previos", que no constituyen otra cosa que el "capital cultural" de nuestros alumnos

Tampoco podría quedar fuera de estas consideraciones la realidad social en la que están inmersos quienes van a recibir una propuesta de enseñanza y aprendizaje que tiene pretensiones de "renovadora". Para los actuales y futuros alumnos, la Guerra Fría, la Crisis de los Misiles de 1962, el Muro de Berlín y aun la disolución de la Unión Soviética, son hechos que viven en "ese país distinto", configurado en un ayer ajeno a sus expectativas y vivencias contemporáneas. El objeto de enseñar historia a los jóvenes de hoy debería transitar por sendas que los guíen en 
el desarrollo de competencias analiticas, críticas e interpretativas, por medio de las cuales puedan actuar sobre su realidad social que, en el caso de Latinoamérica, se constituye en un objeto de imprescindible abordaje operando como un desafío para las nuevas generaciones.

La enseñanza de la historia contribuyó tal vez como ninguna otra disciplina social a la formación de la

\section{BIBLIOGRAFÍA}

Aristóteles, Poética. Traducción y notas de Alfredo Llanos. Buenos Aires: Santiago Rueda Editores.

Ausubel, D. P., Novak, J. y Hanessian, J. (1983). Psicología educativa. Un punto de vista cognoscitivo. México: Trillas.

AYMARD, A. y AUBOyeR, J. (1958, 1977). EI clasicismo espiritual y estético: la vida intelectual. En: Maurice Crouzet (dir.). Historia general de las civilizaciones. Oriente y Grecia Antigua. Barcelona: Destino.

Birgin, Alejandra. (1999). El trabajo de enseñar. Entre la vocación y el mercado: las nuevas reglas del juego. Buenos Aires: Troquel.

BURKE, P. (1993). Formas de hacer historia. Madrid: Alianza Editorial.

Carretero, M. (1996). Construir y enseñar las ciencias sociales y la historia. Madrid: Visor

Collingwood, R. G. (1946 y 1976). Idea de la historia. México: Fondo de Cultura Económica.

Freire, P. (1999). Política y educación. México: Editores Siglo XXI.

Fontana, J. (1982). Historia. Análisis del pasado y proyecto social. Barcelona: Critica.

Furet, F. (1989). Pensar la Revolución Francesa, Barcelona: Crítica.

HeRÓDOTO. (1968). Los nueve libros de la Historia. Buenos Aires: El Ateneo. ciudadanía en los estados iberoamericanos emergentes de la disolución del mundo colonial en el siglo XIX. Si esto fue asi, hoy su objeto no deberia ser otro que el de contribuir a lograr un ejercicio inclusivo de la ciudadanía, la cual no debería agotarse en la conquista de los derechos políticos, sino también hacerse extensiva al logro en plenitud de los derechos sociales. Al terminar aquí estas líneas, permítasenos hacerlo con las palabras de ese gran espectador de nuestro tiempo que es Eric Hobsbawm: "Pero no abandonemos las armas, ni siquiera en los momentos más difíciles. La injusticia social debe seguir siendo denunciada y combatida. El mundo no mejorará por sí solo..." 26

${ }^{26}$ E. Hobsbawm. (2003). Años interesantes. Una vida en el siglo XX, op. cit.
Hobsbawm, E. (1992). Los ecos de la Marsellesa. Barcelona: Crítica.

(2003). Años interesantes: una vida en el siglo $X X$. Barcelona-Buenos Aires: Crítica-Planeta.

HUARTE. G. (1998). La naturaleza epistemológica del conocimiento histórico y su transposición didáctica. En: Anuario del IEHS, 13. Tandil, Argentina: Grafikart, UNCPBA.

(2005). Identidades, representaciones y construcción de la conciencia histórica. Los contenidos de historia en el tercer ciclo de la educación general básica en la Argentina. En: Corbalán, María Alejandra. Enredados por la educación, la cultura y la politica. Buenos Aires: Editorial Biblos.

et al. (1998). El tercer ciclo de la educación general básica bonaerense: ¿Encuentro de dos mundos? En: Corbalán, A. y Russo, H. Educación, actualidad $\theta$ incertidumbre. Tandil, Argentina: UNCPBA

Y VAN DER HORTS, C. (2002). Historiografia y enseñanza de la historia en la Argentina, 1880-1910. En: Castro, Inés (coord.). Visiones Latinoamericanas. México: Universidad Autónoma de México.

LLoyd, C. (1986). Explanations in Social History. Oxford: Basil Blackwell.

MARTIGNONI, L. (2002). La transformación educativa de los noventa en Argentina. Tercer ciclo de la educación general básica. En: Castro, Inés (coord.). Visiones Latinoamericanas. México: Universidad Nacional Autónoma de México.
Pereyra, C. (1988). Historia: ¿Para qué? México: Fondo de Cultura Económica.

Ricofur, P. (1995). Tiempo y narración. Tomo I. Madrid: Siglo XXI Editores.

Schaff, A. (1971, 1994). Historia y verdad. Barcelona: Planeta-De Agostini.

Shellmits, D. J. (1987). El proyecto de enseñanza de la historia 13-16 años del British Council. En: La geografia y la historia, dentro de las ciencias sociales hacia un currículum integrado. Madrid: MEC.

TOPOLSKY, J. (1982). Historia económica, nuevos enfoques, nuevos problemas y Metodología de la historia. Madrid: Cátedra.

Veyne, P. (1984). Cómo se escribe la Historia. Foucault revoluciona la Historia. Madrid: Alianza Editorial.

VILAR, P. (1982). Iniciación al vocabulario del análisis histórico. Barcelona: Crítica.

White, H. (1992). El contenido de la forma. México: Fondo de Cultura Económica.

WRIGHT, G.. H. Von. (1979). Explicación y comprensión. Madrid: Alianza Editorial.

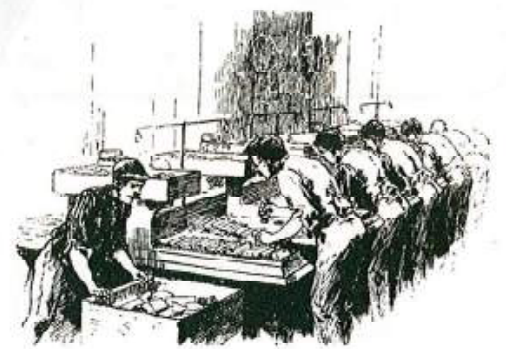

